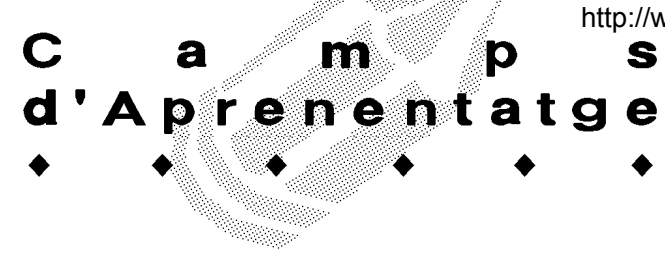

\title{
EL CAMP D'APRENENTATGE "CAN SANTOI"
}

\author{
Equip de coordinació pedagògica del Camp d'Aprenentatge
}

El Camp d'Aprenentatge Can Santoi està situat al barri de La Rierada de la vila de Molins de Rei, a la comarca del Baix Llobregat. La seu del Camp d'Aprenentatge és el Centre d'Educació Ambiental i de Lleure Can Santoi (CEAL CAN SANTOI).

L'àmbit de treball correspon principalment al de les ciències de la natura i comprèn aspectes d'ecologia, zoologia, botànica, geologia, meteorologia i cartografia, entre d'altres, i s'emmarca en el territori de la terra baixa mediterrània, dominat per l'alzinar i les brolles amb pi blanc, al sector nord-occidental de la serra de Collserola.

Els destinataris de les activitats del Camp són, preferentment, els alumnes d'edats compreses entre els 10 i 18 anys (cicle superior d'Ensenyament Primari, Ensenyament Secundari Obligatori, Batxillerats i Cicles Formatius).

\section{Objectius}

A grans trets i de forma genèrica, podem resumir els objectius que pretenem en els següents:

- Interessar les noies i els nois en el coneixement $\mathrm{i}$ estudi del medi natural i/o social mitjançant el contacte directe amb aquests fent ús de procediments i instrumental adequats.

- Desenvolupar les capacitats d'observació, experimentació i anàlisi, potenciant alhora la curiositat i creativitat dels alumnes.

- Potenciar el treball de camp com a eina didàctica bàsica per al coneixement de qualsevol entorn natural, així com desvetllar i potenciar actituds de respecte envers la natura.

- Contribuir a la incorporació al sistema educatiu d'objectius clars d'educació ambiental, sempre imbricats dins el currículum escolar.

\section{Modalitats d'estada i relació d'activitats}

L'oferta actual del Camp contempla diverses modalitats d'estada.

Estades De Més D’Un Dia

- Estades temàtiques de tres dies, en les quals els alumnes desenvolupen amb un cert aprofundiment un tema monogràfic en funció dels seus interessos curriculars, ja siguin unitats de programació o bé crèdits comuns o variables; a tall d'exemple podem anotar els següents:

Meteorologia (ESO): ús d'aparells meteorològics, interpretació de mapes i predicció del temps i aplicacions concretes a l'estudi del medi.

Ecosistemes (ESO): estudi de diversos ecosistemes (riera, sòl, bosc...) fent especial esment als factors abiòtics i biòtics i les interrelacions que existeixen entre ells.

Cartografia (ESO): tècniques d'orientació amb ús de mapes topogràfics, altímetres, brúixoles; realització de mapes temàtics i plànols; fotografia aèria.

Vegetació (ESO): estudi de les comunitats vegetals més freqüents a Collserola mitjançant inventaris florístics i transectes fisiognòmics de la vegetació.

Collserola (Cicle Superior d'EP): visió integrada de paisatge, vegetació i riera.

Funcionalitat dels ecosistemes terrestres (BATX): biomassa i producció d'un bosc de pi blanc; estudi funcional de la riera i determinació de la qualitat de les seves aigües.

- Estades de crèdit de síntesi, adreçades a l'ESO, de tres, quatre o cinc dies de durada. Els alumnes desenvolupen activitats -l'eix central de les quals sempre és el treball de camp i/o laboratori- que prèviament s'han concretat entre el centre i el Camp d'Aprenentatge. Té, òbviament, un caire interdisciplinari, més enllà de les ciències experimentals.

- Estades "a la carta" de tres, quatre o cinc dies. El centre escull les activitats que l'interessin dins l'oferta que el Camp té en la modalitat d'estades d'un dia de durada que a continuació detallarem.

\section{EstadesD'Un Sol Dia}

Les estades d'un dia són activitats dissenyades com a suport puntual a unitats de programació de l'Ensenyament Primari o crèdits comuns i variables de l'Ensenyament Secundari. Aquesta oferta va adreçada, bàsicament, als centres de la comarca per raons òbvies de desplaçament. A tall de resum, hem agrupat les 


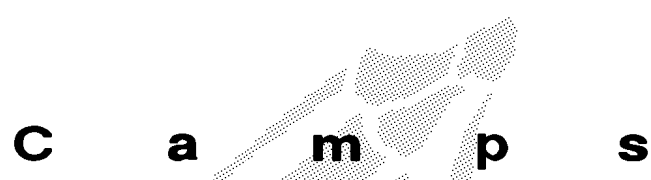 d'Aprenentatge \\ $\bullet \bullet \bullet \bullet$}

activitats en sis àmbits:

\section{Orientació, cartografia i relleu}

Itinerari d'orientació (Sector Puig d'Olorda).

Adreçada a: alumnes d'ESO.

Objectiu específic: aportar pautes procedimentals concretes per a un ús correcte dels instruments per a l'orientació en el camp. Reconeixement dels elements de relleu del Baix Llobregat i interpretació del paisatge.

\section{El temps meteorològic}

Observació i mesura del temps atmosfèric.

Adreçada a: alumnes d'ESO.

Objectiu específic: utilitzar i conèixer els aparells de meteorologia més habituals. Elaborar i interpretar gràfics i mapes del temps.

\section{Les roques}

Itinerari geològic de les roques sedimentàries.

Adreçada: a alumnes d'ESO.

Objectiu específic: aplicar tècniques de geologia de camp, reconèixer la litologia d'algunes roques sedimentàries $i$ interpretar la seva gènesi.

\section{El món vegetal}

Els bolets.

Adreçada a: alumnes d'ESO, adaptable al cicle superior d'EP.

Objectiu específic: observació, recol-lecció, descripció i identificació de bolets. La seva ecologia.

\section{Les criptògames.}

Adreçada a: segon cicle d'ESO.

Objectiu específic. reconèixer la morfologia i ecologia dels principals grups de criptògames presents a la zona (molses, falgueres...).

L'alzinar, La brolla i El bosc de ribera.

Adreçada a: alumnes d'ESO.

Objectiu específic: reconèixer els trets principals d'aquestes comunitats vegetals, especialment pel que fa a les condicions ambientals, la fisiognomia (estructura) i la composició florística.

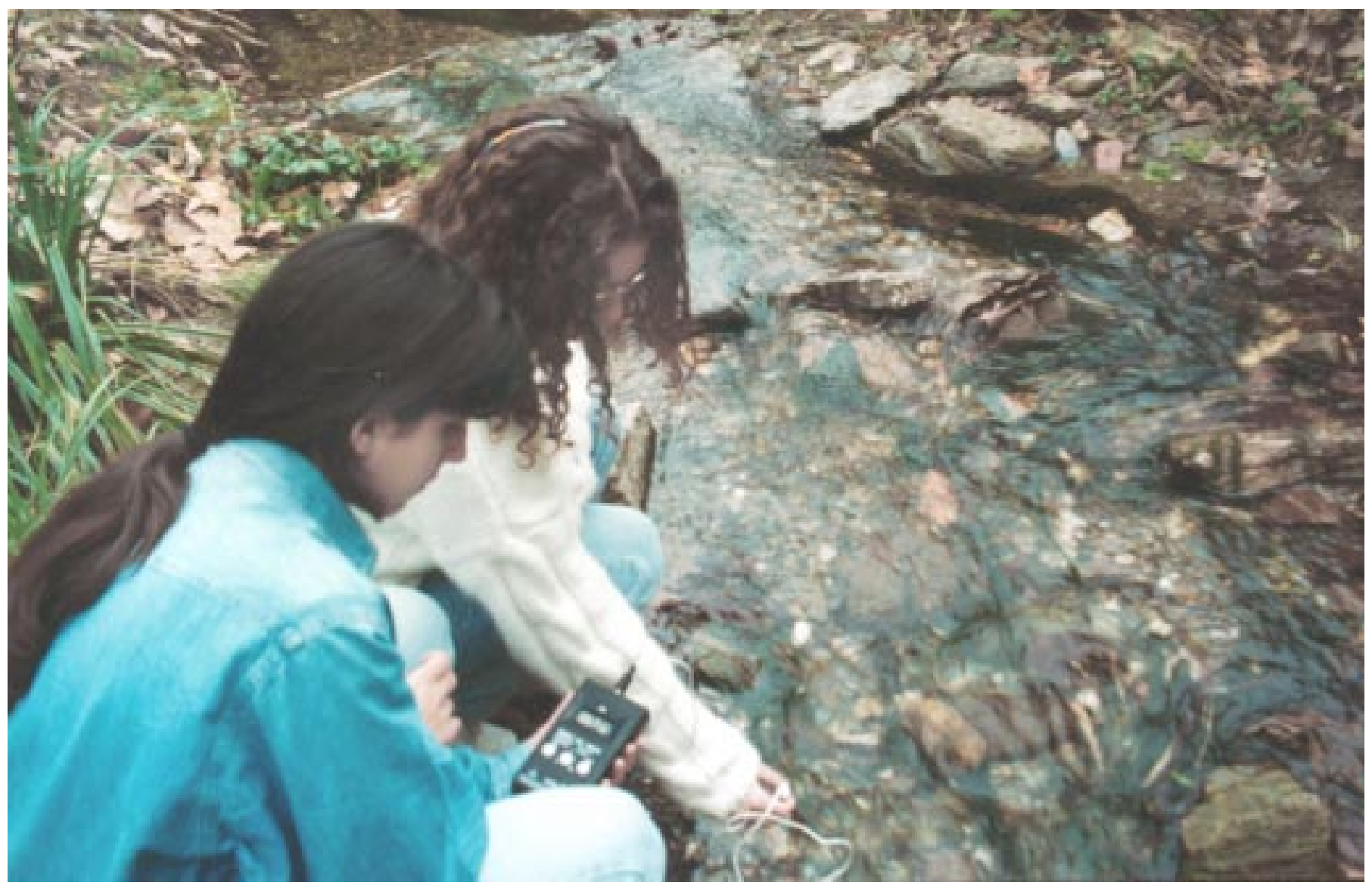

Alumnes mesurant la qualitat de l'aigua de la riera, mitjançant la mesura de paràmetres físico-químics (temperatura, $\mathrm{pH}$, conductivitat elèctrica...). 


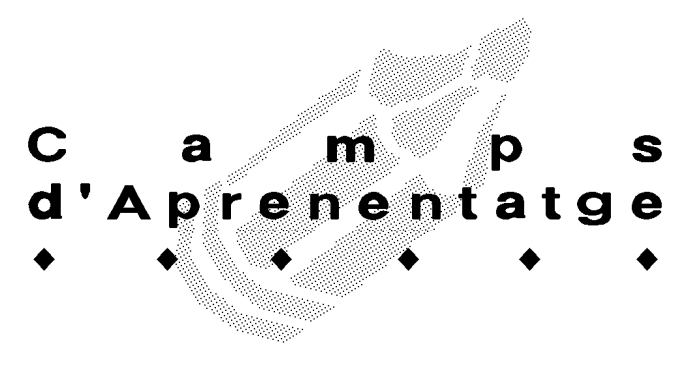

Dinàmica dels ecosistemes

La diversitat dels éssers vius.

Adreçada a: alumnes d'ESO.

Objectiu específic: observar, descriure i classificar una mostra significativa de la diversitat dels éssers vius presents en ecosistemes propers, fent especial esment als trets diferencials dels cinc regnes; utilitzar mètodes matemàtics senzills per al càlcul i representació gràfica de la biodiversitat.

\section{La riera de Vallvidrera.}

Adreçada a: alumnes d'ESO; també existeix una versió per al cicle superior d'EP, titolada: La riera.

Objectiu específic: aproximació a l'estudi de l'ecologia de la riera: factors biòtics i abiòtics, reconeixement i descripció de macroinvertebrats, elaboració de xarxes tròfiques, determinació de la qualitat de l'aigua.

Introducció a l'ecologia del soll.

Adreçada a: alumnes d'ESO.

Objectiu específic: reconèixer els components biòtics i abiòtics més repesentatius que configuren el sòl. Establir possibles relacions entre ells.

Biomassa i producció d'un bosc.

Adreçada a: Batxillerat.

Objectiu específic: aplicar tècniques i proceiments d'ecologia forestal. Realitzar una estimació de la biomassa i producció d'una parcel-la de bosc. Interpretar l'estat actual del bosc i dissenyar propostes per a una correcta gestió.

Les comunitats vegetals / i ll: estudi comparatiu.

Existeixen dues versions: cicle superior d'EP i ESO.

Objectiu específic: realitzar un estudi comparatiu entre diferents comunitats vegetals (alzinar, brolla i bosc de ribera) per tal d'interpretar els diferents processos d'adaptació d'aquestes comunitats al seu microclima concret.

\section{El cicle de la matèria.}

Adreçada a: Cicle superior d'EP.

Objectiu específic: identificar el cicle de la matèria a la natura tot reconeixent-ne els elements que el configuren.

\section{$\underline{\text { Recursos del medi i sostenibilitat }}$}

\section{El compostatge.}

Adreçada a: alumnes d'ESO.

Objectiu específic: identificar el cicle de la matèria a la natura tot reconeixent-ne els elements que el configuren; elaborar i fer el seguiment de piles de compost com a mètode per a la reducció i reutilització dels residus orgànics domèstics.

L'energia solar i les seves aplicacions.

Adreçada a: ESO, Batxilerat i Cicles Formatius de
Grau mitjà i Superior.

Objectiu específic: realitzar un itinerari didàctic a les instal-lacions d'energia solar de què disposa la seu del Camp, i construir models a escala reduïda d'alguns dispositius d'aprofitament d'energia solar.

És important ressenyar que en tots el casos cal assistir a una trobada de coordinació, prèvia a l'estada dels alumnes, per tal de conèixer la metodologia de treball $i$ els recursos didàctics del Camp, $i$ elaborar conjuntament un pla de treball adequat a cada grup. En alguns casos es contemplen activitats prèvies i posteriors a l'estada que caldrà tenir en compte, així com el compromís per part del centre d'avaluar la tasca realitzada al Camp.

\section{Instal-lacions}

El Camp d'Aprenentatge Can Santoidisposa de 38 places de capacitat i compta, a banda dels espais de manutenció i allotjament, amb: laboratori equipat amb els aparells i estris necessaris, biblioteca (especialitzada en temes d'ecologia, botànica, zoologia, geologia, cartografia, meteorologia, energies renovables, medi ambient, etc), sala d'usos múltiples, infermeria, instal-lacions esportives, calefacció i electricitat a partir d'energia solar, estació meteorològica, etc. Edifici adaptat a persones amb discapacitats.

\section{Altres serveis}

- Assessorament a professionals de l'ensenyament en temes de l'àmbit del Camp.

- Préstec de materials i recursos didàctics.

- Suport als Projectes d'Investigació de l'alumnat de Batxillerat.

Si desitgeu més informació, podeu adreçar-vos a:
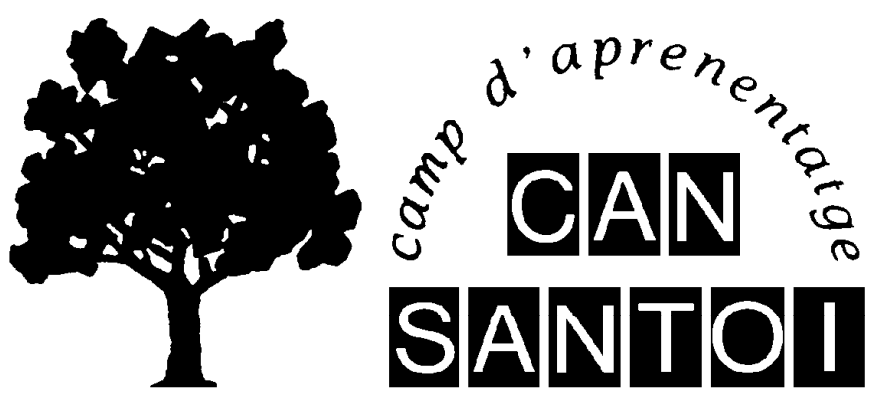

Av. Montserrat, $s / n$. La Rierada 08750 Molins de Rei (Baix Llobregat) Tel/fax: (93) 6802931

E-mail: ccastilla@pie.xtec.es 